\title{
Effect of pecan nut expeller meal on quality characteristics of gluten-free muffins
}

\author{
L. Marchetti ${ }^{a, *}$, M.S. Acuña ${ }^{b}$, S.C. Andrés ${ }^{a}$ \\ ${ }^{a}$ Centro de Investigación y Desarrollo en Criotecnología de Alimentos (CIDCA, CONICET-CICPBA-UNLP), Facultad de Ciencias Exactas, UNLP, 47 y 116, La Plata, \\ 1900, Argentina \\ ${ }^{\mathrm{b}}$ Facultad de Ciencias Exactas, UNLP, 47 y 116, La Plata, 1900, Argentina
}

\section{A R T I C L E I N F O}

\section{Keywords:}

Celiac disease

Baked goods

By-product

Texture

Storage

\begin{abstract}
A B S T R A C T
To improve gluten-free (GF) muffin quality the pecan nut expeller (PNE) has been incorporated at two levels (20 and $30 \mathrm{~g} / 100 \mathrm{~g}$, P20 and P30, respectively) as a partial replacement for traditional flour mix, while water was adjusted to obtain iso-viscous batters than the GF-control. Process yield, aw, texture, color, crumb structure, and moisture were analyzed. PNE inclusion improved water-binding properties and let to obtain softer crumbs with more pores. Texture, crumb moisture, thermic transitions, fatty acid profile, and antioxidant capacity were studied during their storage. Product hardness increased over storage time but in a lower proportion for PNEmuffins, while chewiness increased for control and remained stable for them $(2.43 \mathrm{~N})$. Besides, starch retrogradation enthalpy diminished through the storage when the expeller was included. Higher antioxidant capacities were obtained in PNE-muffins, which were slightly lower by the storage time. Muffin's fatty acid profiles were almost stable during their storage in agreement with TBARS value that showed slight differences with time. Also, PNE-muffins presented higher PUFA contents (18.13 and $20.9 \mathrm{~g} / 100 \mathrm{~g}$ for P20 and P30, respectively) with respect to the control. These results reflected that pecan nut expeller could be successfully incorporated into a GF- muffin with improvements in their physicochemical characteristics, PUFA content, antioxidant activity, and storage stability.
\end{abstract}

\section{Introduction}

People with celiac disease (CD) are considered genetically susceptible individuals (Delgado, Muñoz, Allué, \& Esteban, 2008) with permanent intolerance to gluten, the protein group present in some cereals (Kupper, 2005). Its consumption in small quantities produces villus atrophy of the intestinal mucosa which conducts to alterations in nutrients absorption. When the mentioned proteins are strictly omitted, the villus is normalized.

Therefore, the food industry must afford a variety of products suitable for celiac and also the non-celiac people that choose a gluten-free diet, which greatly outnumbers the patients affected by CD (Tovoli et al., 2015). Thus, the exponential growth of the gluten-free (GF) market, which has become one of the most profitable food industry segments, is happening (Krupa-Kozak et al., 2019). The development of gluten-free baked goods implies a technological challenge due to the inability of GF flours to form a dough with adequate viscoelastic characteristics. Various studies have been carried out to develop GF products using biopolymers such as xanthan gum or combinations of starches and hydrocolloid that can replace the absence of gluten but even the matrices have rheological and organoleptic properties that need to be optimized (Gómez \& Colina, 2019; Herranz, Canet, \& Álvarez, 2017; Paz, 2019). Likewise, the concern for the nutritional quality of these products has increased, since their consumption is characterized by poor intake of fiber, minerals, and complex carbohydrates, with high energy levels. For this reason, many studies have focused on the enrichment of GF baked goods with components such as cereals, pseudo-cereals, legume flour, protein concentrates, fibers, etc. (Capriles \& Arêas, 2014; Ziobro, Witczak, Juszczak, \& Korus, 2013).

The industrial pressing of pecan nut (Carya illinoinensis) to obtain the oil produces a large amount of by-product called "expeller", generally intended for balanced animal food. Its composition in macro and micronutrients makes the expeller nutritionally beneficial since it still maintains a high lipid content (50\%), characterized by a low level of saturated and high level of unsaturated fats (oleic and linoleic acids), as well as high contents of tocopherols (especially $\beta$ - and $\gamma$-tocopherol), and

\footnotetext{
* Corresponding author.

E-mail address: marchetti.lucas@quimica.unlp.edu.ar (L. Marchetti).
} 
polyphenolic substances with potent antioxidant capacity (Kornsteiner, Wagner, \& Elmadfa, 2006). Therefore, as the nut consumptions, it could be associated with a lower incidence of cardiovascular mortality and the improvement of the blood lipid profile (decrease in total and LDL cholesterol, and triglycerides) (Yang, Liu, \& Halim, 2009). Besides, its fiber, protein, micronutrient, and vitamin contents make it a potential ingredient for incorporation into baked goods.

This work aimed to provide alternative uses for pecan nut expeller by its inclusion in gluten-free muffins. Thus the objectives were: i) to obtain GF-muffin raw batters containing pecan nut expeller at two levels with similar viscosity to a control formulation, ii) to evaluate the effect of the pecan nut expeller inclusion on GF-muffin physicochemical characteristics, fatty acid profile, and antioxidant properties, and iii) to study their storage stability in polyethylene at $20{ }^{\circ} \mathrm{C}$ to ensure its shelf life.

\section{Materials and methods}

\subsection{Materials and components}

All formulations were made with the same common components: cassava starch, corn starch, and white rice flour (Ying Yang, Remedios de Escalada, Argentina) that made up the GF-mixture in 2:2:6 ratio, respectively; white granulated sugar (Ledesma, Tucumán, Argentina), whole dried egg (Ovobrand, Brandsen, Argentina), dried skim milk (fat content: 1.5 g/100 g; La Serenísima, Mastellone Hnos S.A., Buenos Aires, Argentina), refined high oleic acid sunflower oil (Molino Cañuelas, Cañuelas, Argentina), vanilla essence (Saporiti, Buenos Aires, Argentina), xanthan gum (Anedra, Research GA, Buenos Aires, Argentina), sodium chloride (Anedra, Research GA, Buenos Aires, Argentina), sodium bicarbonate (Biopack, Buenos Aires, Argentina), and tartaric acid (Biopack, Buenos Aires, Argentina).

Pecan nut expeller meal (PNE) was provided by Nucana (Entre Ríos, Argentina) after pressing recently harvested pecan nuts. PNE was processed immediately after the reception with a commercial food processor (Universo, Rowenta, Germany, $14 \mathrm{~cm}$ blade), sieved through a 350 $\mu \mathrm{m}$ mesh in order to obtain a homogenous coarse-like powder, and stored in vacuum bags (Cryovac BB4L, $\mathrm{PO}_{2}: 0.35 \mathrm{~cm}^{3} \mathrm{~m}^{-2} \mathrm{day}^{-1} \mathrm{kPa}^{-1}$ at $23{ }^{\circ} \mathrm{C}$, Sealed Air Co., Buenos Aires, Argentina) at $10^{\circ} \mathrm{C}$. PNE composition (lipids $51.4 \pm 0.1 \mathrm{~g} / 100 \mathrm{~g}$, total dietary fiber $13.6 \pm 0.1 \mathrm{~g} / 100 \mathrm{~g}$, proteins $13.2 \pm 0.01 \mathrm{~g} / 100 \mathrm{~g}$, carbohydrates $11.96 \pm 0.07 \mathrm{~g} / 100 \mathrm{~g}$, moisture $5.66 \pm 0.03 \mathrm{~g} / 100 \mathrm{~g}$, and ashes $3.67 \pm 0.05 \mathrm{~g} / 100 \mathrm{~g}$ ), as well as its fatty acid (FA) profile (saturated FA 6.09\%, monounsaturated FA $63.27 \%$, and polyunsaturated FA $29.93 \%$ ) were determined in previous work (Marchetti, Romero, Andrés, \& Califano, 2017).

GF-muffins were formulated according to Table 1. Three formulations were made: a control-muffin (C-muffin) following one common recipe, and two PNE-muffins with the GF-mixture partially replaced by

Table 1

GF-muffin formulations: C and PNE-muffins (P20 and P30).

\begin{tabular}{llll}
\hline Formulation & $\mathrm{C}$ & P20 & P30 \\
\hline GF-mixture & 31.24 & 28.18 & 26.65 \\
Pecan nut expeller & 0 & 6.25 & 9.37 \\
High oleic sunflower oil & 10.01 & 6.82 & 5.23 \\
Water & 30.48 & $30.48+4.5^{*}$ & $30.48+8^{*}$ \\
Sugar & 21.17 & 21.17 & 21.17 \\
Dried egg & 3.1900 & 3.1900 & 3.1900 \\
Dried skim milk & 2.3600 & 2.3600 & 2.3600 \\
Vanilla essence & 0.4000 & 0.4000 & 0.4000 \\
Tartaric acid & 0.3805 & 0.3805 & 0.3805 \\
Sodium bicarbonate & 0.3805 & 0.3805 & 0.3805 \\
Sodium chloride & 0.2305 & 0.2305 & 0.2305 \\
Xanthan gum & 0.1502 & 0.1502 & 0.1502 \\
TOTAL & 100 & $100+4.5^{*}$ & $100+8^{*}$ \\
\hline
\end{tabular}

$*+4.5$ and +8 , are the amount of extra water added to P20 and P30 formulations respectively in order to obtain iso-viscous batters.

$* *$ GF $=$ Gluten-Free; $\mathrm{C}=$ Control; PNE = Pecan Nut Expeller.
PNE at two levels, 20 and $30 \mathrm{~g} / 100 \mathrm{~g}$ (P20 and P30, respectively), taken into account previous results (Marchetti, Califano, \& Andrés, 2018). For PNE-muffins oil addition was reduced considering the proportion of lipids incorporated with the PNE to keep a constant level among all formulations. Also, water addition was increased in PNE-muffins to obtain iso-viscous batters that resulted in flow curves significantly similar to C-muffin (Struck, Gundel, Zahn, \& Rohm, 2016).

\subsection{Iso-viscous batter preparation}

For all muffin formulations, the same procedure was followed: egg and milk powders were first mixed with water and vanilla essence and let to rest for $10 \mathrm{~min}$ for hydration. Afterward, high oleic sunflower oil was incorporated and emulsified with a handheld homogenizer (Braun Mq 300, Braun, Buenos Aires, Argentina) for $1 \mathrm{~min}$ at $1100 \mathrm{rpm}$. Meanwhile, GF-mixture, pecan nut expeller (for P20 and P30), salts, and white sugar were blended. Then, liquid and solid ingredients were gently mixed and homogenized with a commercial food processor (Universo, Rowenta, Erbach, Germany) for $1 \mathrm{~min}$, at $150 \mathrm{rpm}$.

Initially, PNE- and C-muffin batters were prepared with the same amount of water $(30.48 \mathrm{~g} / 100 \mathrm{~g})$. Then, flow curves were determined with a rotational viscometer (Brookfield, Middleboro, MA, USA). In this way, it was possible to know the rheological behavior of the mixtures and make the necessary adjustments by adding extra water to PNEbatters and reach viscosities similar to the C-batter (iso-viscous batters).

\subsection{Batters' viscosity determination}

The apparent viscosities of the batters were determined at $20{ }^{\circ} \mathrm{C}$ using a digital RVT Brookfield Viscometer (Brookfield Engineering Laboratories, Stoughton, MA, USA). Appropriate spindles with six different speeds $(2.5,5,10,20,50$, and $100 \mathrm{rev} / \mathrm{min})$ were used to obtain the correct dial readings which were taken at $3 \mathrm{~min}$ intervals, to allow enough time for them to stabilize. Two readings were taken for each sample, and the mean dial reading and speed were corrected by the corresponding factor, supplied by the instrument manufacturer, to obtain the shear stress and shear rate.

Several PNE-batters, prepared with $30.48 \mathrm{~g} / 100 \mathrm{~g}$ of water and increasing amounts of it.

PNE-batters were prepared initially with $30.48 \mathrm{~g}$ water/100 $\mathrm{g}$ as the C-batter and their viscosities were measured. To obtain iso-viscous batters new ones were prepared adding different amounts of water until there was no significant difference among the flow curves.

\subsection{Muffin cooking}

Paper cups placed in metallic muffin pans were filled with portions of $65 \pm 0.1 \mathrm{~g}$ batter. Groups of 12 muffins were baked in a pre-heated convective oven (Ariston FM87-FC, Ariston, Fabriano, Italy) at $180{ }^{\circ} \mathrm{C}$ for $32 \mathrm{~min}$. After cooking, their surfaces were sprayed with potassium sorbate $(0.2 \mathrm{~g} / 100 \mathrm{ml}$ water $)$ and cooled at room temperature.

For their characterization, muffins were stored $24 \mathrm{~h}$ in hermetic Ziploc ${ }^{\circledR}$ pouches (C. S. Johnson\&Sons de Argentina S.A.I.C., Buenos Aires, Argentina) to avoid moisture loss until determinations were done. Four batches (12 muffins each) per formulation were prepared and studied.

A storage test was performed to study the evolution of several quality parameters within time. Four new batches of twelve muffins each for Cand PNE-muffins were prepared $(\mathrm{N}=4 \times 12)$. They were cooked, and cooled in the described way and kept in Ziploc ${ }^{\circledR}$ pouches (C. S. Johnson\&Sons de Argentina S.A.I.C., Buenos Aires, Argentina). Muffins were kept at $20^{\circ} \mathrm{C}$ for up to 20 days or until mold growth was observed. 


\subsection{Muffin characterization}

\subsubsection{Process yield}

Process yield ( 3 replicates per batch, 4 batches per formulation) was determined by weighting the raw batter and the corresponding baked product and expressed as $\mathrm{g} / 100 \mathrm{~g}$ of the initial sample weight.

\subsubsection{Product height}

The height of cooked products removed from their paper cups was measured from base to the highest top using an electronic digital caliper (Schwyz, Schwyz, Switzerland) (3 replicates per batch, 4 batches per formulation).

\subsubsection{Crumb moisture and water activity}

Crumb from muffin center was obtained and its moisture was determined in an oven at $105{ }^{\circ} \mathrm{C}$ until constant weight ( 3 replicates per batch, 2 batches per formulation). Water activity $\left(a_{w}\right)$ was determined on muffin crumbs at $25^{\circ} \mathrm{C}$ using an AquaLab Dew Point Series 4 4TEV kit (Decagon Devices INC. MA, USA) (3 replicates per batch, 2 batches per formulation).

\subsubsection{Crumb structure}

Digital image analysis was used to characterize crumb structure (3 replicates per batch, 4 batches per formulation). Crumb slices were horizontally cut from the muffin center. Images (600 DPI) were captured using a flat-bed scanner (HP 4500 Hewlett Packard, Palo Alto, CA, USA) and analyzed using Image $\mathrm{J} 1.48 \mathrm{q}$ software (National Institutes of Health, Stapleton, NY, USA, available at http://rsb.info.nih.gov/ij/) that uses the contrast between two phases (pores and solids parts) in the image. First, the scanned color images were converted to grayscale and then binarized to obtain the pore area fraction as total pore area/total area of the slice $\left(\mathrm{cm}^{2} / \mathrm{cm}^{2}\right)$, the diameter of pores, and the pore density (number of pores $/ \mathrm{cm}^{2}$ ). Diameter limits of 0.1 and $6 \mathrm{~mm}$ were established.

Pore volume was calculated as:

$V=\frac{\pi D^{3}}{6}$

where $D$ is the diameter of the pore (mm).

$\mathrm{D}[4,3]$, volumetric diameter (De Brouckere diameter, $\mathrm{mm}$ ), reflects the size of pores majority of the gas volume. It is most sensitive to the presence of large pores in the size distribution and is identical to the weight equivalent mean if the density is constant. It was calculated as:

$D[4,3]=\frac{\sum_{i}^{N} n_{i} D_{i}^{4}}{\sum_{i}^{N} n_{i} D_{i}^{3}}$

where $D_{i}$ is the diameter of the $i$ th pore (mm) and $n_{i}$ is the number of pores with $D_{i}$ diameter (mm).

Pore specific perimeter was calculated as the sum of all pores perimeters divided by the total area of the slice.

\subsubsection{Crumb texture}

Texture Profile Analysis (TPA) was performed on muffin crumbs (Bourne, 1974) (6 replicates per batch, 2 batches per formulation) at controlled room temperature $\left(25^{\circ} \mathrm{C}\right)$. Samples $(25 \mathrm{~mm}$ thick and $29 \mathrm{~mm}$ diameter) were cut from the crumb and compressed twice to $30 \%$ of their original height between flat plates using a TAXT2i Texture Analyzer (Stable Micro Systems, Godalming, UK) interfaced with a computer, using the software supplied by Texture Technologies Corp. In these experiments, the probe diameter was $75 \mathrm{~mm}$ and was operated at $0.5 \mathrm{~mm} / \mathrm{s}$. Hardness (peak force of first compression cycle, $\mathrm{N}$ ), cohesiveness (ratio of positive areas of the second cycle to the area of the first cycle, $\mathrm{J} / \mathrm{J}$, dimensionless), adhesiveness (negative force area of the first bite represented the work necessary to pull the compressing plunger away from the sample, J), chewiness (hardness $\mathrm{x}$ cohesiveness $\mathrm{x}$ springiness, N), springiness (the distance of the detected height of the product on the second compression divided by the original compression distance, $\mathrm{mm} / \mathrm{mm}$, dimensionless) and resilience (area during the withdrawal of the first compression divided by the area of the first compression, $\mathrm{J} / \mathrm{J}$, dimensionless) were determined.

\subsubsection{Crumb and crust color}

Color determinations were performed using a Chroma Meter CR-400 colorimeter (Minolta Co., Ramsey, New Jersey, USA) on the surface of transversally cut muffin slices for crumb color and directly on the crust for crust color. CIE-LAB parameters (lightness, L; redness, $\mathrm{a}^{*}>0$ or greenness, $a^{*}<0$, and yellowness, $b^{*}>0$ or blueness $b^{*}<0$ ) were determined ( 3 replicates per batch, 4 batches per formulation). The aperture size was $8 \mathrm{~mm}$ and a D65 illuminant was employed. Before each series of measurements, the instrument was adjusted using a white ceramic tile $\left(L^{*}=98.45, a^{*}=-0.10, b^{*}=-0.13\right.$; Minolta calibration plate).

\subsection{Determinations during muffin storage}

\subsubsection{Physicochemical characteristic}

Crumbs' moisture content, water activity, and texture were determinate through the storage period as described.

\subsubsection{Thermal analysis}

Differential scanning calorimetry (DSC) was performed on a Q100 modulated DSC (TA Instruments, USA). At different storage times, crumb samples were accurately weighed (approximately $15 \mathrm{mg}$ ) and sealed in hermetical aluminum pans. An empty pan was used as a reference. Runs were performed according to the following protocol: samples were stabilized at $25^{\circ} \mathrm{C}$ and heated to $125^{\circ} \mathrm{C}$ at $4{ }^{\circ} \mathrm{C} / \mathrm{min}$. After each run, a pinhole was made on the cover of every pan and then dried at $105^{\circ} \mathrm{C}$ for water content measurement. Enthalpies $(\Delta \mathrm{H})$, expressed as $\mathrm{J} /$ $\mathrm{g}$ of dry matter, were obtained by integrating the areas under the DSC curves using the software for thermal analysis (TA Instruments Universal Analysis 2000; TA Instruments, USA) and dividing these areas by the weight of the corresponding sample. A sigmoidal baseline was used to calculate peak areas. Peak transition temperatures were also determined from DSC thermograms (2 replicates per batch, 2 batches per formulation).

\subsubsection{Antioxidant capacity}

For extract preparation, $1 \mathrm{~g}$ coarse ground muffins were accurately weighed and extracted for $60 \mathrm{~min}$ in $15 \mathrm{~mL}$ of ethanol. Mixtures were centrifuged at $3000 \mathrm{~g}$ for $15 \mathrm{~min}$ at $4{ }^{\circ} \mathrm{C}$ and supernatants were properly diluted according to the assay.

The capacity to scavenge the 2,2-diphenyl-1-picrylhydrazyl $\left(\mathrm{DPPH}^{\bullet}\right.$ ) free radical was monitored (Marchetti et al., 2017). Various concentrations of extracts $(0.5 \mathrm{ml})$ were mixed with $2.7 \mathrm{ml}$ of DPPH ethanolic solution $(0.2 \mathrm{mmol} / \mathrm{l})$. The mixture was shaken vigorously and left to stand for $90 \mathrm{~min}$ in the dark. The reduction in $\mathrm{DPPH}^{\bullet}$ radical was measured by monitoring absorbance at $517 \mathrm{~nm}$.

The radical-scavenging activity of the extracts was determined also by the 2,20-azino-bis(3-ethylbenzothiazoline-6-sulfonic acid) radical $\left(\right.$ ABTS $^{\bullet+}$ ) cation discoloration assay (Marchetti et al., 2017). Different concentrations of extracts $(0.5 \mathrm{ml})$ were mixed with $2 \mathrm{ml}$ of the ABTS ${ }^{\bullet+}$ solution and the mixtures were shaken for $7 \mathrm{~min}$. The reduction in $\mathrm{ABTS}^{\bullet+}$ radical was determined by reading the absorbance at $734 \mathrm{~nm}$.

A calibration curve was performed with Trolox for both DPPH ${ }^{\bullet}$ and $\mathrm{ABTS}^{\bullet+}$ assays. So antioxidant capacity was expressed as Trolox equivalent capacity (TEAC, mg of Trolox per $100 \mathrm{~g}$ muffin).

\subsubsection{Lipid oxidation and fatty acid profiles}

Lipid oxidation during muffin storage was monitored by the thiobarbituric acid reactive substances (TBARS) in quadruplicate according to Pennisi-Forell, Ranalli, Zaritzky, Andrés, and Califano (2010). Results 
were expressed as mg malondialdehyde (MDA)/kg product.

At the beginning and the end of the storage, lipid phases were obtained of the different GF-muffins by the Folch method using a chloroform-methanol mix $(2: 1, \mathrm{v} / \mathrm{v})$. For the derivatization process, 60 $\mathrm{mg}$ of the obtained oil was combined with $4 \mathrm{ml} n$-hexane and $300 \mu \mathrm{l}$ methanolic $\mathrm{KOH}(2 \mathrm{~mol} / \mathrm{l})$. The solution was mixed vigorously and shaken in a vortex for $20 \mathrm{~min}$. After that, $0.5 \mathrm{~g}$ of $\mathrm{Na}_{2} \mathrm{SO}_{4}$ was added and finally, $1 \mathrm{ml}$ of the upper phase was separated to be injected.

The fatty acid methyl ester (FAME) content was assayed by Shimadzu GC-MS model QH-2010 Ultra and Hewlett Packard's (HP) model HP-6890. The methyl esters of the fatty acids (FAME) were analyzed with a capillary column DB-23 (30 m long, $0.25 \mathrm{~mm}$ diameter x $250 \mu \mathrm{m}$ thickness). The injector and detector temperatures were 250 and $280^{\circ} \mathrm{C}$, respectively. A temperature ramp was made, with an initial temperature of $50{ }^{\circ} \mathrm{C}$. In a first stage, a rate of $25^{\circ} \mathrm{C} / \mathrm{min}$ was used up to $175^{\circ} \mathrm{C}$ and then $4{ }^{\circ} \mathrm{C} / \mathrm{min}$ from $175^{\circ} \mathrm{C}$ to $230^{\circ} \mathrm{C}$, maintaining the latter for $15 \mathrm{~min}$. The total running time was $34.75 \mathrm{~min}$. Fatty acids were identified by comparison of the retention times $\left(t_{R}\right)$ of each peak with an external standard Supelco 37 component FAME MIX, $100 \mathrm{mg}$ Neat. Catalog. No. 18919-1AMP.

\subsection{Statistical analysis}

Analyses of variance (ANOVA) were conducted separately on dependent variables studied considering each formulation as a level in a one-way factorial design. For simultaneous pairwise comparisons, the least significant differences (LSD) test was chosen. Differences in means and F-tests were considered significant when $\mathrm{P}<0.05$. All statistical procedures were computed using SYSTAT software (SYSTAT, Inc., Evanston, IL). Experimental data were reported as mean values, standard error of the mean (SEM) is informed between parenthesis.

\section{Results and discussion}

\subsection{GF-muffin batter viscosities}

The viscosity of a raw batter is related to the physicochemical properties of the baked product, such as crumb hardness, chewiness, or product volume (Grigelmo-Miguel, Carreras-Boladeras, \& Martín-Belloso, 1999; Sudha, Baskaran, \& Leelavathi, 2007). To avoid differences among muffins due to different batter viscosities, PNE-muffin batters were adjusted by adding extra water than the control to obtained similar iso-viscous GF-batters (Struck et al., 2016).

Shear stress vs. shear rate curves of the different GF-batters are shown in Fig. 1. It could be seen that P20 and P30-batters showed curves that were similar to the C-batter curve. PNE-batters without the corresponding extra water were also included in order to show the alteration of their viscosity regarding the C-batter.

All curves were suitably fitted with the power-law model, where $\tau$ is the shear stress, $\mathrm{K}(\mathrm{Pa} \cdot \mathrm{sn})$ the viscosity factor, and $\mathrm{n}$ the flow behavior index, with an $\mathrm{R}^{2}>0.996$ in all cases. Flow behavior of all the batters corresponded to pseudoplastic non-Newtonian fluids.

When comparing C, P20 without extra water, and P30 without extra water, it can be concluded that PNE addition increase batter consistencies, probably because of a great swelling process of PNE fibers, that would compete with the other macromolecules for the available water and oil, and then modified the rheology of the batters (Farooq \& Boye, 2011). According to the total dietary fiber content of the expeller, its inclusion increased the batter dietary total fiber from almost zero in C-batter to 0.81 and $1.18 \mathrm{~g} / 100 \mathrm{~g}$ for P20 and P30, respectively. So, the addition of extra water (Table 1) was necessary to obtain iso-viscous behaviors, as it is shown in Fig. 1, which only significantly affected batter consistencies, resulting in an average $\mathrm{K}$ value of $39.17 \pm 1.27 \mathrm{~Pa}$ among all the iso-viscous batters. On the other hand, the flow index was unchanged among all samples $(\mathrm{n}=0.435 \pm 0.002)$.

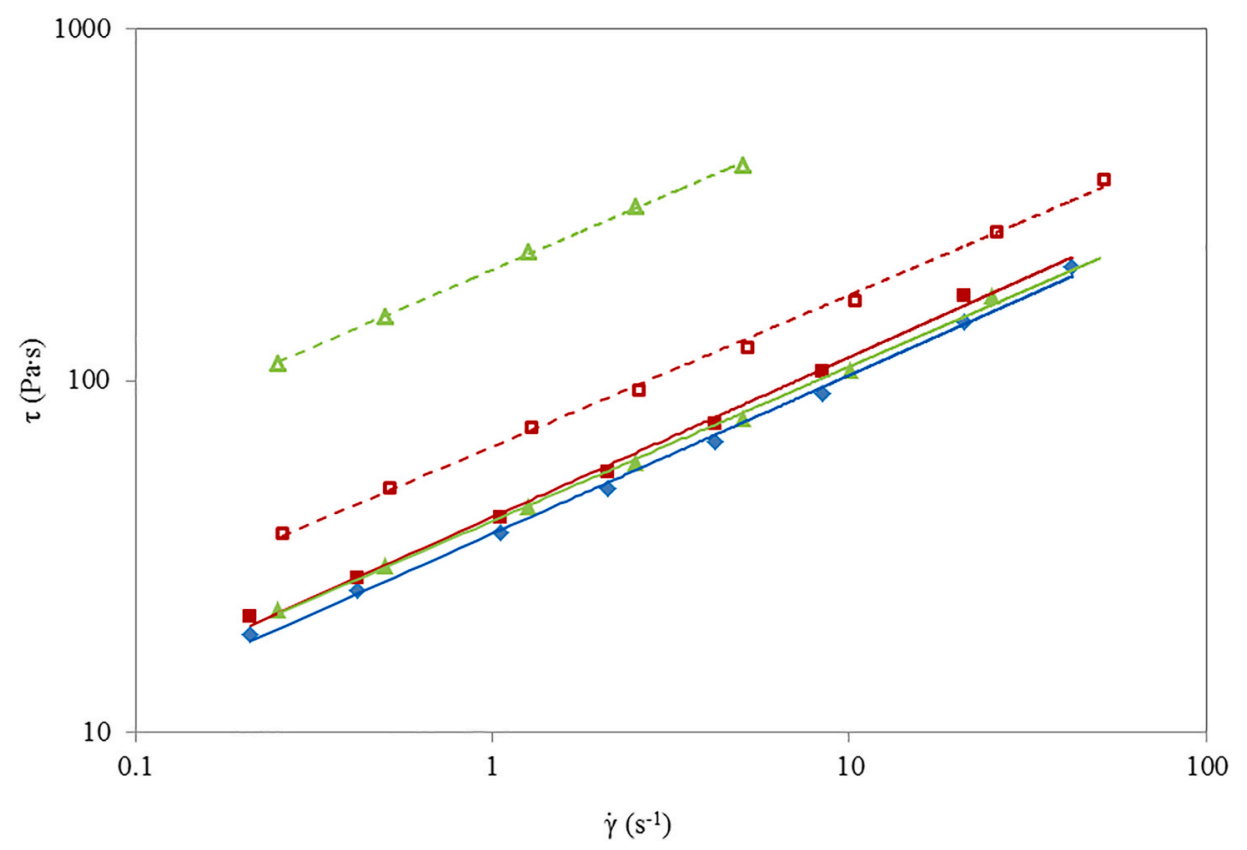

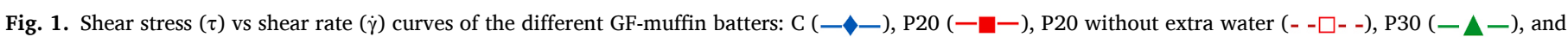
P30 without extra water (-- $\Delta--)$. 


\subsection{GF-muffin physicochemical characteristics}

Process yields were high and greater than $88 \%$ for all GF-muffin formulations (Table 2). Nevertheless, significant differences among them could be observed. The replacement of $20 \%$ of GF-mixture with pecan nut expeller along with the extra-water addition in P20 formulation slightly increased its process yield, while height was unaffected. This could be explained by the large water retention capacity of the expeller (1.83 $\mathrm{g} \mathrm{H}_{2} \mathrm{O} / \mathrm{g}$, Marchetti et al., 2017), which would minimize the weight loss during cooking. Accordingly, the crumb of P20 muffins showed greater moisture content and water activity than the C-muffin (Table 2). This aspect could be the main cause of texture changes when PNE was included in the system. As can be seen in Table 2, the addition of PNE to the batters, in both levels, resulted in small hardness and chewiness decreases, nevertheless, the obtained values were suitable for these products since a softer texture is always desirable (Struck et al., 2016). Besides, elasticity was slightly increased in PNE-muffins while resilience was not significantly modified. An increase in adhesiveness was also observed but it is worth mentioning that these parameter values were markedly low in concordance with the typical texture profile of these products.

Table 2 also shows the image analysis results of the three muffin formulations. The volumetric diameter ( $[4,3]$ ), which constitutes the average diameter of the pores, was unaffected with the PNE addition, but pore density and area showed significant changes. P20 and P30 crumbs showed higher pore densities without differences between them, and since the pores were of equal size (same $D[4,3]$ ) their pore area fractions were increased. This leads to muffins with good volume and a considerably porous crumb. Thus matrixes with PNE had structures with more sponge-like characteristics and this is in agreement with texture parameters like hardness and elasticity previously discussed. These aspects are important characteristics of muffin acceptability and sensory quality.
Another product purchase-decisive characteristic is the color. Colorimetric parameters $\left(\mathrm{L}^{*}, \mathrm{a}^{*}\right.$, and $\left.\mathrm{b}^{*}\right)$ of muffin crusts and crumbs are presented in Table 2, and also images of the products are included. The addition of PNE resulted in darker crusts and crumbs than the control GF-muffin since the expeller itself was darker than the GF-mixture (Marchetti et al., 2018; Marchetti, Andrés, Cerruti, \& Califano, 2020). This effect was more accentuated in crumbs. In the crust higher temperatures are reached, prompting coloring reactions in all formulations, which could hinder the PNE effect. Sabani, Lebesi, and Tzia (2009) stated that the original color of the fiber source did not influence on the crust color of gluten-free bread because this is mainly associated with Maillard and caramelization reactions. Related to this point, the crusts of P20 and P30 muffins presented lower $\mathrm{a}^{*}$ and $\mathrm{b}$ * parameters than control, with no significant differences between them, indicating less reddish and yellowish products probably due to a minor extension of the reactions above-mentioned. For the crumbs, since these processes would not occur, the chromatic parameters were shifted by the PNE addition resulting in higher $\mathrm{a}^{*}$ (more redness) and lower $\mathrm{b} *$ (less yellowish).

Decreases in crumb and crust $b^{*}$ and $L^{*}$ parameters were also reported in other studies of gluten-free products with dietary fiber and xanthan gum (Singh, Kaur, Shevkani, \& Singh, 2015).

In general, muffins with partial GF-mixture replacement with pecan nut expeller presented lower lightness and yellowness, and higher redness than typical muffins made with refined flour. These changes are characteristic of fiber-added or fiber-rich products, which consumers interpret as healthier (Walker, Tseng, Cavender, Ross, \& Zhao, 2014).

\subsection{GF-muffin storage}

\subsubsection{Physicochemical and thermal properties}

Fig. 2 shows GF-muffin crumbs 'moisture content and water activity evolution through the storage period. It could be seen that no matter the initial level, both parameters diminished with time. Nevertheless, values

Table 2

Physicochemical characteristics of different GF-muffins, their crumb and crust properties.

\begin{tabular}{|c|c|c|c|}
\hline Determination & $\mathrm{C}$ & P20 & P30 \\
\hline \multicolumn{4}{|l|}{ Muffin characteristics } \\
\hline Process yield (g/100g) & $88.6 \pm 0.3^{\mathrm{b}}$ & $89.7 \pm 0.2^{\mathrm{a}}$ & $89.2 \pm 0.2^{\mathrm{ab}}$ \\
\hline Height $(\mathrm{cm})$ & $4.81^{\mathrm{ab}}$ & $5.02 \pm 0.04^{\mathrm{a}}$ & $4.71^{\mathrm{b}}$ \\
\hline \multicolumn{4}{|l|}{ Crumb characteristics } \\
\hline$a_{w}(\mathbf{a d})$ & $0.9157 \pm 0.0010^{\mathrm{b}}$ & $0.9306 \pm 0.0011^{\mathrm{a}}$ & $0.9402 \pm 0.0007^{\mathrm{a}}$ \\
\hline Moisture content $(\mathrm{g} / \mathbf{1 0 0 g})$ & $31.5 \pm 1.0^{\mathrm{b}}$ & $32.6 \pm 0.4^{\mathrm{a}}$ & $35.1 \pm 0.5^{\mathrm{a}}$ \\
\hline $\mathrm{D}[4,3](\mathrm{cm})$ & $0.36 \pm 0.02^{\mathrm{a}}$ & $0.40 \pm 0.04^{\mathrm{a}}$ & $0.40 \pm 0.01^{\mathrm{a}}$ \\
\hline Pore density $\left(\mathrm{n}^{\circ} / \mathrm{cm}^{2}\right)$ & $8.3 \pm 1.8^{\mathrm{b}}$ & $15.3 \pm 1.1^{\mathrm{a}}$ & $13.8 \pm 0.2^{\mathrm{a}}$ \\
\hline Pore area fraction (\%) & $9.8 \pm 2.6^{\mathrm{b}}$ & $15.8 \pm 2.1^{\mathrm{a}}$ & $18.1 \pm 0.9^{\mathrm{a}}$ \\
\hline Hardness (N) & $7.2 \pm 0.4^{\mathrm{a}}$ & $6.0 \pm 0.4^{\mathrm{b}}$ & $5.8 \pm 0.3^{\mathrm{b}}$ \\
\hline Elasticity $(\mathrm{cm} / \mathrm{cm})$ & $0.858 \pm 0.006^{\mathrm{b}}$ & $0.887 \pm 0.004^{\mathrm{a}}$ & $0.893 \pm 0.002^{\mathrm{a}}$ \\
\hline Cohesiveness $(\mathrm{J} / \mathrm{J})$ & $0.435 \pm 0.004^{\mathrm{a}}$ & $0.378 \pm 0.005^{\mathrm{b}}$ & $0.444 \pm 0.003^{\mathrm{a}}$ \\
\hline Chewiness (N) & $2.79 \pm 0.15^{\mathrm{a}}$ & $2.08 \pm 0.09^{\mathrm{b}}$ & $2.30 \pm 0.10^{\mathrm{b}}$ \\
\hline Resilience (J/J) & $0.330 \pm 0.008^{\mathrm{a}}$ & $0.325 \pm 0.004^{\mathrm{a}}$ & $0.345 \pm 0.006^{\mathrm{a}}$ \\
\hline Adhesiveness (J) & $0.006 \pm 0.006^{\mathrm{b}}$ & $0.110 \pm 0.092^{\mathrm{ab}}$ & $0.198 \pm 0.151^{\mathrm{a}}$ \\
\hline$L^{*}$ & $71.9 \pm 1.5^{\mathrm{a}}$ & $50.7 \pm 0.5^{\mathrm{b}}$ & $45.0 \pm 0.2^{\mathrm{c}}$ \\
\hline $\mathbf{a}^{*}$ & $0.7 \pm 0.4^{\mathrm{c}}$ & $8.5 \pm 0.1^{b}$ & $8.8 \pm 0.2^{\mathrm{a}}$ \\
\hline $\mathbf{b}^{*}$ & $20.8 \pm 0.4^{\mathrm{a}}$ & $15.0 \pm 0.2^{\mathrm{b}}$ & $12.2 \pm 0.4^{\mathrm{c}}$ \\
\hline \multicolumn{4}{|l|}{ Crust characteristics } \\
\hline $\mathbf{L}^{*}$ & $53.5 \pm 0.7^{\mathrm{a}}$ & $50.0 \pm 0.2^{\mathrm{b}}$ & $49.4 \pm 0.3^{\mathrm{b}}$ \\
\hline$a^{*}$ & $12.7 \pm 0.5^{\mathrm{a}}$ & $10.2 \pm 0.1^{\mathrm{b}}$ & $9.6 \pm 0.1^{\mathrm{b}}$ \\
\hline $\mathbf{b}^{*}$ & $24.00 \pm 1.2^{\mathrm{a}}$ & $16.7 \pm 0.5^{\mathrm{b}}$ & $16.5 \pm 0.5^{\mathrm{b}}$ \\
\hline
\end{tabular}

a-b Different letters on the same row indicate significant differences $(\mathrm{P}<0.05)$. 

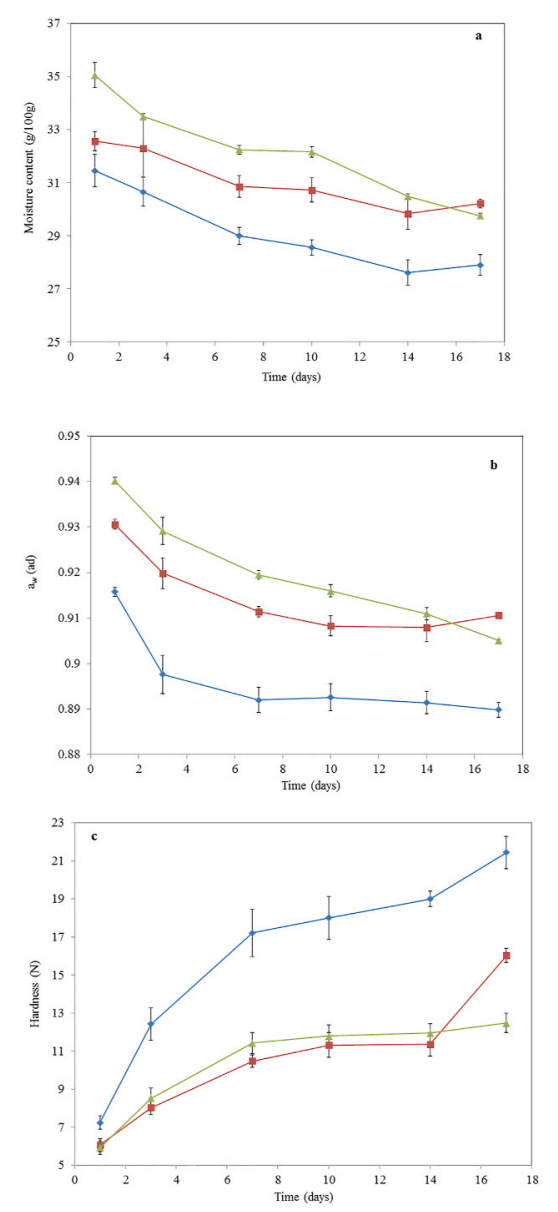
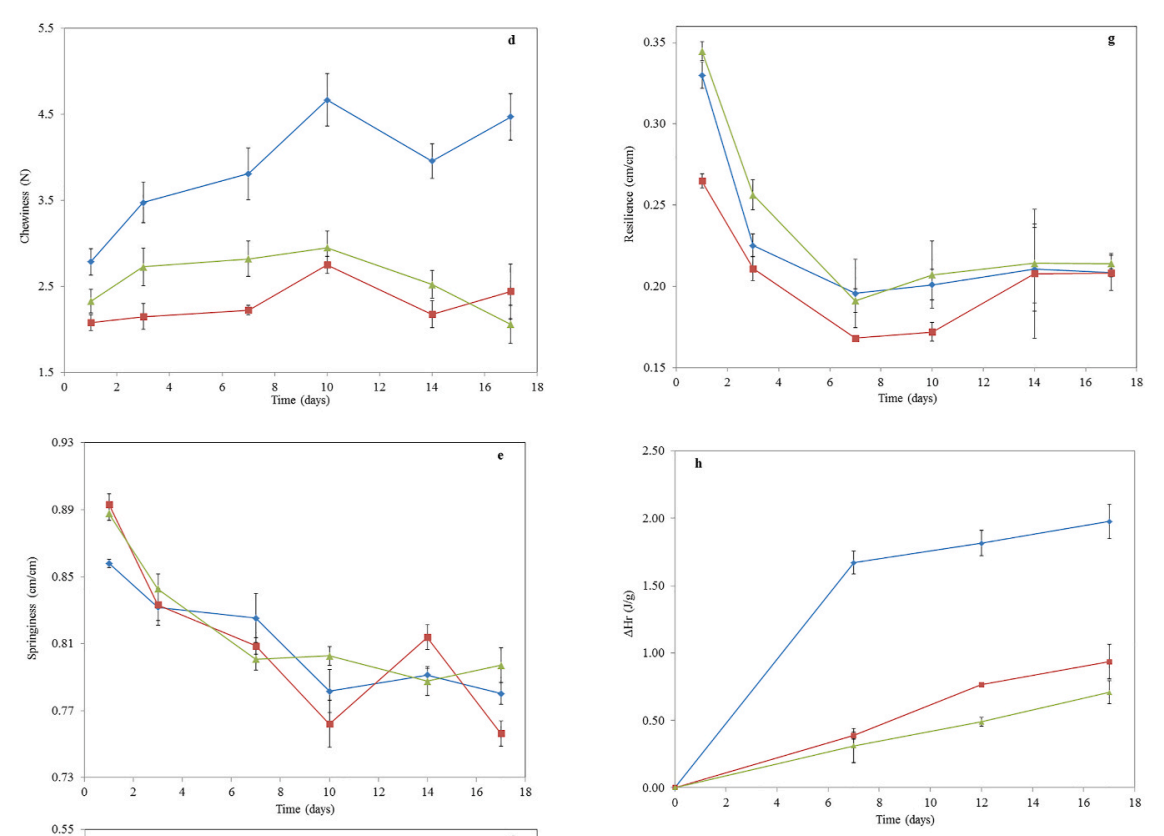

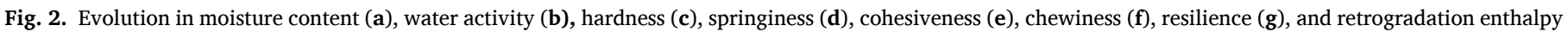

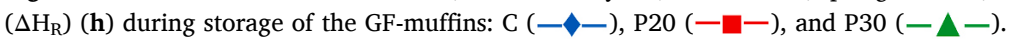

for P20 and P30 muffins were always higher than those of C-muffin.

Simultaneously, hardness increased during storage (Fig. 2 c) but to a lower extent for PNE-muffins. Chewiness (Fig. 2 d) increased for Cmuffins but remained constant for PNE-ones.

Therefore, formulations with PNE presented better stability regarding chewiness, which is related to the energy needed for the chewing process and implies the sensorial quality of the product.

Springiness, cohesiveness, and resilience presented similar tendencies among them (Fig. $2 \mathrm{e}, \mathrm{f}, \mathrm{g}$ ). In the first days of storage, a decrease was observed remaining almost constant beyond, without differences ( $P$ $>0.05$ ) among GF-muffin formulations and therefore, no effect of PNE addition.

These crumb textural changes of smaller magnitude in PNE-muffins would be a consequence of the changes in crumb moisture (water loss) but also probably of the starch retrogradation, an ongoing process that initially involves rapid recrystallization of amylose, which determines the initial hardness of a starch gel, followed by slow recrystallization of amylopectin, which is involved in the staling of bread and cakes (Wang, Li, Copeland, Niu, \& Wang, 2015). GF-muffin retrogradation enthalpies' $\left(\Delta \mathrm{H}_{\mathrm{R}}\right)$ (Fig. $2 \mathrm{~h}$ ) were significantly affected by storage time and formulations $(P<0.05)$. According to other studies, GF-muffin retrogradation enthalpies increased over the storage time (Demirkesen, Campanella, Sumnu, Sahin, \& Hamaker, 2014; Santos, Rosell, \& Collar, 2008). For the recently baked C- and PNE-muffins ( $t=0 \mathrm{~d})$, there were no detectable peaks in their thermograms. With storage time, their retrogradation enthalpies increased, but in a much less proportion when pecan nut expeller was included in the formulations (P20 and P30 muffins).

Agents that compete with starch for water or reduce the effectiveness of leached amylose to form a gel network can retard or inhibit retrogradation (Wang et al., 2015). Considering that pecan nut expeller has an important water absorption capacity (WAC $=1.83 \mathrm{gH}_{2} \mathrm{O} / \mathrm{g}$, Marchetti et al., 2017), the main differences could be explained by the less water availability in the PNE-systems. Besides, due to the PNE-muffin lower starch content and the fiber-released amylose interaction that would limit amylose-amylose hydrogen bonds formation, retrogradation could be diminished.

\subsubsection{Antioxidant properties}

By both methods employed, PNE-muffins showed up to three or four times more antioxidant capacities than the control (Table 3), and, despite the drops they showed at 17storage-days, their levels remained high. Among different cakes and pulses, pecan nut cake, or expeller showed a very high amount of antioxidant capacity (Marchetti et al., 2017). High contents of catechin, epicatechin, gallic, and ellagic acids were observed for pecan nut expeller (Sarkis et al., 2014). These authors informed that despite tocopherols and part of the phospholipids were removed during oil extraction a high phenolic content remained in the defatted residues. In this way, the cakes have great potential as suitable and economically viable by-products for recovery of the phenolic compounds or adding to enrich other products.

\subsubsection{Fatty acid profile and lipid oxidation}

TBARS number was slightly affected by both formulation and storage time as can be seen in Table 3. At the initial of storage ( $t=0 \mathrm{~d}$ ), C-muffin TBARS values were higher than for PNE-muffins, which could be explained by the antioxidant effect of PNE. At 17 days of storage, no differences were found among formulations. 
Table 3

Antioxidant capacity (DPPH and ABTS methods) and lipid oxidation (TBARS) of GF-muffins at initial and 17 days of storage.

\begin{tabular}{|c|c|c|c|c|}
\hline & $\begin{array}{l}\text { Storage time } \\
\text { (days) }\end{array}$ & C & $\mathrm{P} 20$ & P30 \\
\hline \multirow[t]{2}{*}{$\begin{array}{l}\text { DPPH (mg TROLOX/ } \\
\quad 100 \mathrm{~g} \text { ) }\end{array}$} & 0 & $9.7 \pm 3.0^{\mathrm{cA}}$ & $\begin{array}{l}35.2 \pm \\
3.7^{\mathrm{bA}}\end{array}$ & $\begin{array}{l}46.9 \pm \\
0.4^{\mathrm{aA}}\end{array}$ \\
\hline & 17 & $7.3 \pm 0.5^{\mathrm{cA}}$ & $\begin{array}{l}24.6 \pm \\
1.8^{\mathrm{bB}}\end{array}$ & $\begin{array}{l}43.7 \pm \\
0.8^{\mathrm{aB}}\end{array}$ \\
\hline \multirow[t]{2}{*}{$\begin{array}{l}\text { ABTS (mg } \\
\text { TROLOX/100g) }\end{array}$} & 0 & $\begin{array}{l}2.1 \pm \\
0.3^{\mathrm{bA}}\end{array}$ & $\begin{array}{l}23.2 \pm \\
1.3^{\mathrm{aA}}\end{array}$ & $\begin{array}{l}19.2 \pm \\
0.4^{\mathrm{aA}}\end{array}$ \\
\hline & 17 & $\begin{array}{l}1.8 \pm \\
0.6^{\mathrm{aA}}\end{array}$ & $8.0 \pm 1.8^{\mathrm{bB}}$ & $\begin{array}{l}11.5 \pm \\
1.4^{\mathrm{bB}}\end{array}$ \\
\hline \multirow[t]{2}{*}{$\begin{array}{l}\text { TBARS (mg MDA/ } \\
\text { kg) }\end{array}$} & 0 & $\begin{array}{l}0.63 \pm \\
0.00^{\mathrm{aA}}\end{array}$ & $\begin{array}{l}0.54 \pm \\
0.03^{\mathrm{bA}}\end{array}$ & $\begin{array}{l}0.53 \pm \\
0.04^{\mathrm{bB}}\end{array}$ \\
\hline & 17 & $\begin{array}{l}0.57 \pm \\
0.04^{\mathrm{aA}}\end{array}$ & $\begin{array}{l}0.56 \pm \\
0.02^{\mathrm{aA}}\end{array}$ & $\begin{array}{l}0.64 \pm \\
0.01^{\mathrm{aA}}\end{array}$ \\
\hline
\end{tabular}

${ }^{a-b}$ Different letters in each row indicate significant differences $(P<0.05)$.

${ }^{\mathrm{A}-\mathrm{B}}$ Different capital letters in each column indicate significant differences $(\mathrm{P}<$ 0.05).

Fatty acid profiles were obtained at the initial and 17 days of storage but results showed no variations between profiles for each muffin formulation, so averages values of the main fatty acids were obtained and shown in Table 4. Nevertheless, P30 showed some significant slight increase in TBARS that was not reflected in the fatty acid profile which could indicate the early beginning of an oxidation process probably due to the higher PUFA content (Table 3).

Since the expeller had an important amount of pecan nut oil that was taken into account in the formulation of the products (Table 1), PNEmuffins showed some significant differences in their fatty acids profiles' respect to the control. Higher proportions of palmitic (16:0), linoleic (18:2), and linolenic (18:3) acids, and lower oleic (18:1) acid, were determined in PNE-muffins concerning C-muffins. When the total proportions of SFA, MUFA, and PUFA were calculated, PNE-muffins showed higher PUFA and lower MUFA content than C-muffins, and in a higher proportion with higher PNE levels.

\section{Conclusions}

The use of the pecan nut expeller, an oil industry by-product with excellent nutritional characteristics, as an ingredient in food products, makes it a value-added resource and constitutes an opportunity for the production chain sustainability, a priority issue today.

Gluten-free muffins with PNE in partial replacement of the traditional GF-mixtures showed higher moisture content, softer and more aerated crumbs. During their storage, the PNE-muffins presented less marked texture changes correlated with a slower rate of starch retrogradation. At the same time, PNE addition addresses the nutritional problem of a large part of gluten-free foods, often high in calories and not fortified, by the increase in fiber content (about $1 \mathrm{~g} / 100 \mathrm{~g}$ ), the polyunsaturated fatty acids level (an increase of 65-91\%), and their antioxidant capacity.

\section{CRediT authorship contribution statement}

L. Marchetti: Conceptualization, Methodology, Data curation, Writing - original draft. M.S. Acuna: Visualization, Investigation. S.C. Andrés: Supervision, Project administration, Funding acquisition, Writing - review \& editing.

\section{Declaration of competing interest}

All authors have participated in (a) conception and design, or analysis and interpretation of the data; (b) drafting the article or revising it critically for important intellectual content; and (c) approval of the final version.
Table 4

Main fatty acids of different GF-muffin formulations. Average values obtained at the beginning and the end of the storage.

\begin{tabular}{llll}
\hline \multirow{2}{*}{ Fatty acid } & \multicolumn{3}{l}{ GF-muffin formulation } \\
\cline { 2 - 4 } & C & P20 & P30 \\
\hline C 1 1 :0 & $0.09 \pm 0.01^{\mathrm{a}}$ & $0.09 \pm 0.01^{\mathrm{a}}$ & $0.08 \pm 0.01^{\mathrm{a}}$ \\
C 16:0 & $5.88 \pm 0.08^{\mathrm{a}}$ & $6.74 \pm 0.26^{\mathrm{b}}$ & $6.94 \pm 0.06^{\mathrm{b}}$ \\
C 16:1 & $0.14 \pm 0.01^{\mathrm{a}}$ & $0.13 \pm 0.06^{\mathrm{a}}$ & $0.14 \pm 0.01^{\mathrm{a}}$ \\
C 18:0 & $3.30 \pm 0.02^{\mathrm{a}}$ & $3.28 \pm 0.05^{\mathrm{a}}$ & $3.22 \pm 0.05^{\mathrm{a}}$ \\
C 18:1 n-9 cis & $79.4 \pm 0.4^{\mathrm{a}}$ & $71.0 \pm 0.4^{\mathrm{b}}$ & $68.4 \pm 0.4^{\mathrm{c}}$ \\
C 18:2 n-6 cis & $10.4 \pm 0.2^{\mathrm{a}}$ & $17.1 \pm 0.2^{\mathrm{b}}$ & $20.0 \pm 0.3^{\mathrm{c}}$ \\
C 18:3 n-3 & $0.40 \pm 0.07^{\mathrm{a}}$ & $1.00 \pm 0.07^{\mathrm{b}}$ & $0.99 \pm 0.12^{\mathrm{b}}$ \\
C 20:0 & $0.16 \pm 0.02^{\mathrm{a}}$ & $0.14 \pm 0.01^{\mathrm{a}}$ & $0.15 \pm 0.01^{\mathrm{a}}$ \\
C 20:1 n-9 & $0.20 \pm 0.02^{\mathrm{a}}$ & $0.21 \pm 0.02^{\mathrm{a}}$ & $0.22 \pm 0.02^{\mathrm{a}}$ \\
SFA & $9.3 \pm 0.3^{\mathrm{a}}$ & $10.3 \pm 0.4^{\mathrm{a}}$ & $10.2 \pm 0.2^{\mathrm{a}}$ \\
MUFA & $79.7 \pm 0.4^{\mathrm{c}}$ & $71.4 \pm 0.5^{\mathrm{b}}$ & $68.7 \pm 0.4^{\mathrm{a}}$ \\
PUFA & $11.0 \pm 0.3^{\mathrm{c}}$ & $18.3 \pm 0.3^{\mathrm{b}}$ & $21.1 \pm 0.4^{\mathrm{a}}$ \\
\hline
\end{tabular}

${ }^{\mathrm{a}-\mathrm{b}}$ Different letters on the same row indicate significant differences $(\mathrm{P}<0.05)$.

This manuscript has not been submitted to, nor is under review at, another journal or other publishing venue.

The authors have no affiliation with any organization with a direct or indirect financial interest in the subject matter discussed in the manuscript.

\section{Acknowledgments}

This research was supported by Consejo Nacional de Investigaciones Científicas y Tecnológicas (CONICET, Argentina) PIP0546, Agencia Nacional de Promoción Científica y Tecnológica (ANPCYT) PICT-20150344 and PICT-2015-2637, and Universidad Nacional de La Plata X-728. In addition, authors thank NUCANA S.A. (Entre Ríos, Argentina), Ovobrand (Brandsen, Argentina), and Saporiti (Buenos Aires, Argentina) for ingredients provided.

\section{References}

Bourne, M. C. (1974). Textural changes in ripening peaches. Canadian Institute of Food Science and Technology Journal, 7(1), 11-15.

Capriles, V. D., \& Arêas, J. A. G. (2014). Novel approaches in gluten-free breadmaking: Interface between food science, nutrition, and health. Comprehensive Reviews in Food Science and Food Safety, 13(5), 871-890.

Delgado, M. P., Muñoz, F. M., Allué, I. P., \& Esteban, M. M. (2008). Cold urticaria and celiac disease. Journal of Investigational Allergology and Clinical Immunology, 18(2), 123.

Demirkesen, I., Campanella, O. H., Sumnu, G., Sahin, S., \& Hamaker, B. R. (2014). A study on staling characteristics of gluten-free breads prepared with chestnut and rice flours. Food and Bioprocess Technology, 7(3), 806-820.

Faroog, Z., \& Boye, J. (2011). Novel food and industrial applications of pulse flours and fractions. Pulse foods: Processing, quality and nutraceutical applications, 283-323.

Gómez, C., \& Colina, J. (2019). Formulation of gluten-free cupcake with hydrocolloids for people with Celiac disease. Bioactive Compounds in Health and Disease, 2(6), 134-148.

Grigelmo-Miguel, N., Carreras-Boladeras, E., \& Martín-Belloso, O. (1999). Development of high-fruit-dietary-fibre muffins. European Food Research and Technology, 210(2), 123-128.

Herranz, B., Canet, W., \& Álvarez, M. D. (2017). Corn starch and egg white enriched gluten-free chickpea flour batters: Physical, functional and rheological properties. International Journal of Food Properties, 20(1), S489-S506.

Kornsteiner, M., Wagner, K.-H., \& Elmadfa, I. (2006). Tocopherols and total phenolics in 10 different nut types. Food Chemistry, 98(2), 381-387.

Krupa-Kozak, U., Drabińska, N., Rosell, C. M., Fadda, C., Anders, A., Jeliński, T., et al. (2019). Broccoli leaf powder as an attractive by-product ingredient: Effect on batter behaviour, technological properties and sensory quality of gluten-free mini sponge cake. International Journal of Food Science and Technology, 54(4), 1121-1129.

Kupper, C. (2005). Dietary guidelines and implementation for celiac disease. Gastroenterology, 128(4), S121-S127.

Marchetti, L., Andrés, S., Cerruti, P., \& Califano, A. (2020). Effect of bacterial nanocellulose addition on the rheological properties of gluten-free muffin batters. Food Hydrocolloids, 98, 105315.

Marchetti, L., Califano, A. N., \& Andrés, S. C. (2018). Partial replacement of wheat flour by pecan nut expeller meal on bakery products. Effect on muffins quality. LWT-Food Science and Technology, 95, 85-91.

Marchetti, L., Romero, L. M., Andrés, S. C., \& Califano, A. N. (2017). Characterization of pecan nut expeller cake and effect of storage on its microbiological and oxidative quality. Grasas Y Aceites, 68(4), 226. 
Paz, G. M. (2019). High protein rice flour in the development of gluten-free muffins and bread. LSU Master's Theses. 4967 https://digitalcommons.lsu.edu/gradschool th eses/4967.

Pennisi-Forell, S., Ranalli, N., Zaritzky, N. E., Andrés, S. C., \& Califano, A. N. (2010). Effect of type of emulsifiers and antioxidants on oxidative stability, colour and fatty acid profile of low-fat beef burgers enriched with unsaturated fatty acids and phytosterols. Meat Science, 86(2), 364-370.

Sabanis, D., Lebesi, D., \& Tzia, C. (2009). Effect of dietary fibre enrichment on selected properties of gluten-free bread. LWT-Food Science and Technology, 42(8), 1380-1389.

Santos, E., Rosell, C. M., \& Collar, C. (2008). Gelatinization and retrogradation kinetics of high-fiber wheat flour blends: A calorimetric approach. Cereal Chemistry, 85(4), 455-463.

Sarkis, J. R., Côrrea, A. P. F., Michel, I., Brandeli, A., Tessaro, I. C., \& Marczak, L. D. (2014). Evaluation of the phenolic content and antioxidant activity of different seed and nut cakes from the edible oil industry. Journal of the American Oil Chemists' Society, 91(10), 1773-1782.

Singh, J. P., Kaur, A., Shevkani, K., \& Singh, N. (2015). Influence of jambolan (S yzygium cumini) and xanthan gum incorporation on the physicochemical, antioxidant and sensory properties of gluten-free eggless rice muffins. International Journal of Food Science and Technology, 50(5), 1190-1197.
Struck, S., Gundel, L., Zahn, S., \& Rohm, H. (2016). Fiber enriched reduced sugar muffins made from iso-viscous batters. LWT-Food Science and Technology, 65, 32-38.

Sudha, M., Baskaran, V., \& Leelavathi, K. (2007). Apple pomace as a source of dietary fiber and polyphenols and its effect on the rheological characteristics and cake making. Food Chemistry, 104(2), 686-692.

Tovoli, F., Masi, C., Guidetti, E., Negrini, G., Paterini, P., \& Bolondi, L. (2015). Clinical and diagnostic aspects of gluten related disorders. World Journal of Clinical Cases: WJCC, 3(3), 275.

Walker, R., Tseng, A., Cavender, G., Ross, A., \& Zhao, Y. (2014). Physicochemical, nutritional, and sensory qualities of wine grape pomace fortified baked goods. Journal of Food Science, 79(9), S1811-S1822.

Wang, S., Li, C., Copeland, L., Niu, Q., \& Wang, S. (2015). Starch retrogradation: A comprehensive review. Comprehensive Reviews in Food Science and Food Safety, 14(5), 568-585.

Yang, J., Liu, R. H., \& Halim, L. (2009). Antioxidant and antiproliferative activities of common edible nut seeds. LWT-Food Science and Technology, 42(1), 1-8.

Ziobro, R., Witczak, T., Juszczak, L., \& Korus, J. (2013). Supplementation of gluten-free bread with non-gluten proteins. Effect on dough rheological properties and bread characteristic. Food Hydrocolloids, 32(2), 213-220. 